International Review of Research in Open and Distributed Learning Volume 19, Number 2

April - 2018

\title{
Online Hunting, Gathering and Sharing - A Return to Experiential Learning in a Digital Age
}

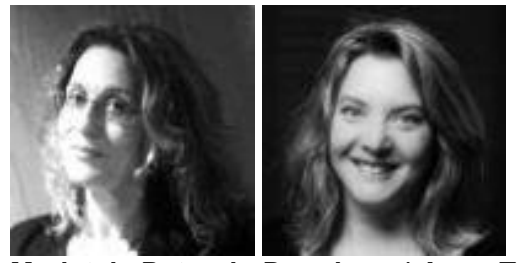

Maristela Petrovic-Dzerdz and Anne Trépanier

Carleton University

\begin{abstract}
Learning through a collective experience by taking part in group activities, such as hunting, gathering, and sharing, has always been a natural, "organic," and "experiential" process where new skills and knowledge, if benefitting the whole group, are accepted, shared, and propagated. Nevertheless, in industrialized societies where specific knowledge and skills are an economical and societal necessity, the learning economy has largely moved to a model where the teachers "harvest" selected knowledge and "put it in a basket" from which students are expected to take from and learn. This learning model has permeated the 21st century digital world, where the main promoted advantage of these new learning environments is still the "individualization of learning," which can result in a very solitary and isolated endeavor; however, it doesn't have to be the case. An example of a successful online university course suggests that carefully crafted online instructional design strategies can contribute to a flexible and rich experiential learning environment. Although they might be physically disconnected, it is possible for learners and a teacher to remain closely interconnected, engaged, and accountable for both individual and group success in knowledge "hunting, gathering, and sharing" activities in a digital age.
\end{abstract}

Keywords: experiential learning, online learning, group learning, digital literacy, educational psychology 


\section{Introduction}

Collective experiences, such as hunting, gathering, raising children, or storytelling have always been a natural, "organic," and "experiential" way of learning new skills and acquiring knowledge. If benefitting the group the individual belongs to, the new skills and knowledge have usually been accepted, shared, and propagated. Both applied research and anthropological intuition show that exploration and experimentation, and in particular knowledge and skill sharing, have always been a key to human learning, which has been understood for centuries as a social activity with individual and group benefits. Gray (2009) describes how hunter-gatherer children have learned and gained social skills largely though play among themselves but also by hearing stories from adults and elders about their experiences, while Geary (2007) similarly points out that children "show a preference for the activities that promote the cross-generational transfer of knowledge in traditional societies" (p. 15). Therefore, as Gray claims, the adults in huntergatherer societies

do not concern themselves much with their children's education. They assume that children will learn what they need to know through their own, self-directed exploration and play. In play, huntergatherer children, on their own initiatives, practice the skills they will need for survival as adults. In their play, they also rehearse and build upon the knowledge, experience, and values that are central to their culture. (Gray, 2009, p. 505)

These spontaneous means of acquiring knowledge and skills are rather different from how we see learning and education today. In industrialized societies, which Harari (2015) reminds us are "the blink of an eye compared to the tens of thousands of years during which our ancestors hunted and gathered" (p. 40), the specific knowledge and skills are an economical and societal necessity, which resulted in a common model where the teachers "harvest" selected knowledge and "put it in a basket" from which students are expected to take from, and learn. Although still occupying the same physical space and time, in this kind of teaching and learning environment, each learner becomes largely responsible for their own learning success, in contrast with traditional group learning and knowledge sharing processes. In addition, in this rather onedimensional exchange between a teacher (through content) and a learner, the latter often becomes deprived of experiences of exploration and learning by immersion in real-life situations, which require applying and testing the theoretical knowledge and newly acquired skills.

This learning model has permeated the 21st century digital world, which enables communities of learners to occupy a virtual space and thus become much larger and diverse than ever before, as well as to be constantly connected. However, the main promoted advantage of these new learning environments is again the "individualization of learning," through statements such as "study at your own pace, when and where it suits you." Although convenient, flexible, and without a doubt a more accessible learning experience, it can be a very solitary and isolated endeavor, but it does not have to be the case. Our experience in migrating an existing traditional face-to-face course online has shown that it is possible to create a sense of community and incorporate even more social activity in an online environment than in the physical classroom.

Teachers now have access to simple yet versatile online applications that allow them to design experiential learning activities where students are first prepared to "hunt and gather" in a digital space, and are consequently encouraged to reflect on their learning experience in the safety of their online community. 
The experiential learning cycle is thus closed through the process of sharing the whole experience with a teacher and classmates.

The process of crowdsourcing course-related content, or "placing the collected fruit in the communal basket for everyone to use" instead of a "fruit basket assembled by a teacher/school," has several learning benefits. Firstly, individual students immediately put in practice what they have learned. Secondly, they are encouraged to reflect on the learning experience and the material they have "harvested," and they get prompt feedback, which provides an opportunity to self-check how well they have understood the notions and concepts introduced by the instructor. Thirdly, by uploading the collected material for a whole class to see, students observe their peers' learning processes and contribute course content, which therefore changes with every term and cohort, making the learning experience unique.

Furthermore, virtual learning spaces, situated in the realm of a digital world dominated by the Internet, require that students build knowledge and skills that allow them to navigate this space, in order to put in practice what they are learning in the course. The combination of related competencies is often referred to as "digital literacy," which the American Library Association's Digital Literacy Task Force defines as "the ability to use information and communication technologies to find, evaluate, create, and communicate information, requiring both cognitive and technical skills" (Digital Literacy, Libraries, and Public Policy, 2013, p. 2). Hence, the learning process in many of today's subjects and topics needs to incorporate experiences of searching for and critically evaluating information found online, as well as being able to communicate and share it in a digital space, while learning from the experiences of others, and with others.

Providing this kind of practice in a virtual classroom, which every learner can decide to join and leave at their will, is not a simple endeavour. It involves the design of some carefully guided activities that require a teacher to not only master the subject, but to also have a high level of digital literacy, and often collaborate with other professionals, such as instructional designers. As Kirschner, Sweller, and Clark (2006) emphasize, engaging students, and especially novices in the field, in learning activities without guidance is likely going to be less effective and can even produce negative learning effects. Furthermore, as Bates (2014) positions, "experiential learning approaches require considerable re-structuring of teaching and a great deal of detailed planning if the curriculum is to be fully covered" (Strengths and Weaknesses of Experiential Learning Models section, para. 4).

\section{Experiential Individual Learning with Communal Benefits}

Preparing students to have in-class informed debates about the sovereignty of Quebec was a major activity in the second-year course Introduction to Quebec Society, taken as an elective for the majority of students enrolled. Students researched primary sources and reviewed secondary sources to help prepare arguments for debate. These were individual activities where students would submit the collected resources to the instructor, as a demonstration of their learning and understanding of differences between primary and secondary sources. Towards the end of the course, students were invited to join either the Yes or the No side in a debate, and prepare arguments with the rest of their group using the material they brought to the 
classroom. Most importantly, the students presented their position and defended it while using the findings of their debate group, while the instructor acted as the debate moderator.

In the online version of the second-year course Introduction to Quebec Society, which has been offered by the School of Indigenous and Canadian Studies at Carleton University (Ottawa) for five consecutive years, the objective was to create a space where such sharing and discussion would still be possible. Ideally, the classical Socratic teaching methods would still be coupled with the implementation of learning through doing. To do so, we designed several communal and experiential learning activities in a Learning Management System Moodle application called Database Activity Module. A good representative of these activities are the primary and secondary source assignments, as well the see, learn, compare, critique activity, leading to the final debate on the future of Quebec.

The online teaching method allows for carefully guided successive and cumulative learning experiences. Students first learn the definition of primary and secondary sources through the online learning module designed using a Moodle lesson activity. The module includes the written definition, explanatory videos recorded by the instructor, and frequent formative assessment activities, which usually take the format of well-designed multiple-choice questions. The multiple-choice questions provide not only immediate feedback on the correctness of a selected answer, but also an explanation of the correct answer, ensuring that students do not acquire wrong information, and at the same time prompting them to revisit the previous content if they provided an incorrect answer. In addition, preamble to the Primary Source assignment, students revise the distinction between primary and secondary sources through a matching activity incorporated in a lesson activity module.

Some of the main learning outcomes in this course include analyzing and integrating information, and sharpening critical thinking and research skills. To accomplish this while practicing to distinguish between two categories of sources, students are sent to two virtual museum exibitions about New France and asked to criticaly analyze both, while learning about displayed objects that come from both of the source categories (Figure 1). 


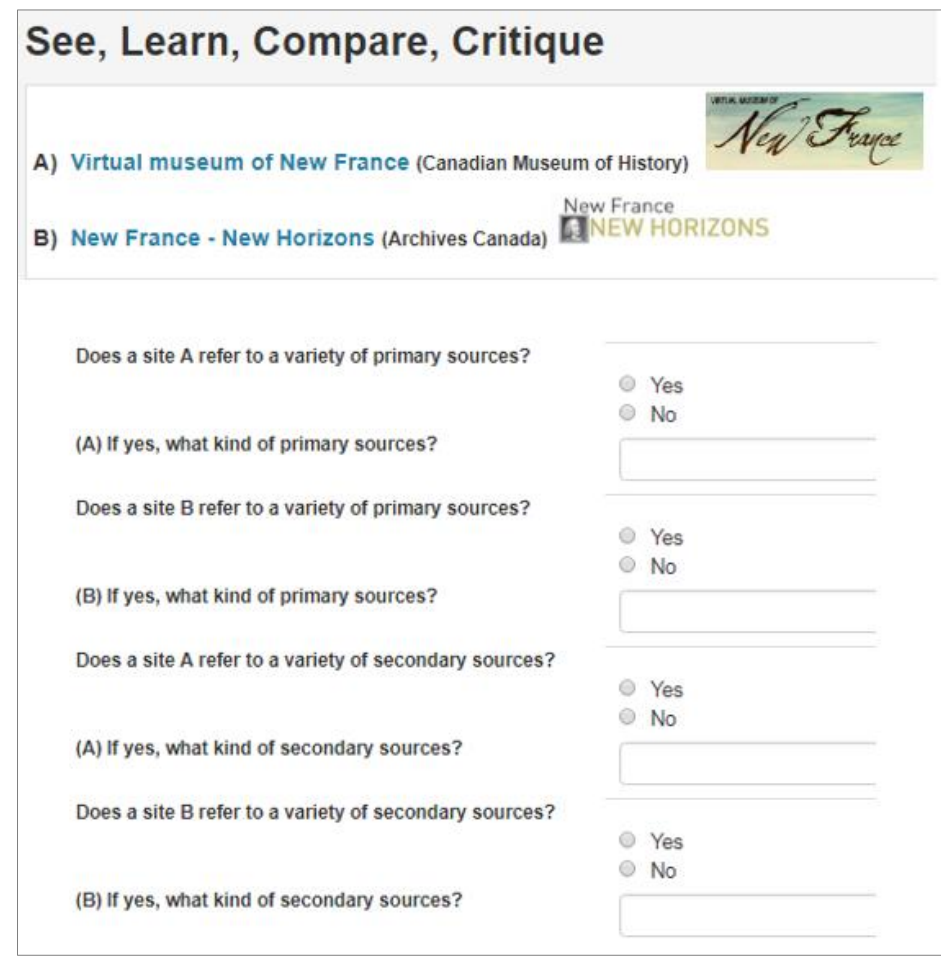

Figure 1. A selection of questions posed in the "see, learn, compare, critique" assignment.

In order to engage in an authentic individual learning experience, students cannot see the entries made by classmates until they submit their own, at which point all entries become visible so that a student can compare their responses with the rest of the class. Each individual submission is open for comments by the teaching staff and students, enabling continuous multi-level discussions between participants as an extension of the learning process (Figure 2).

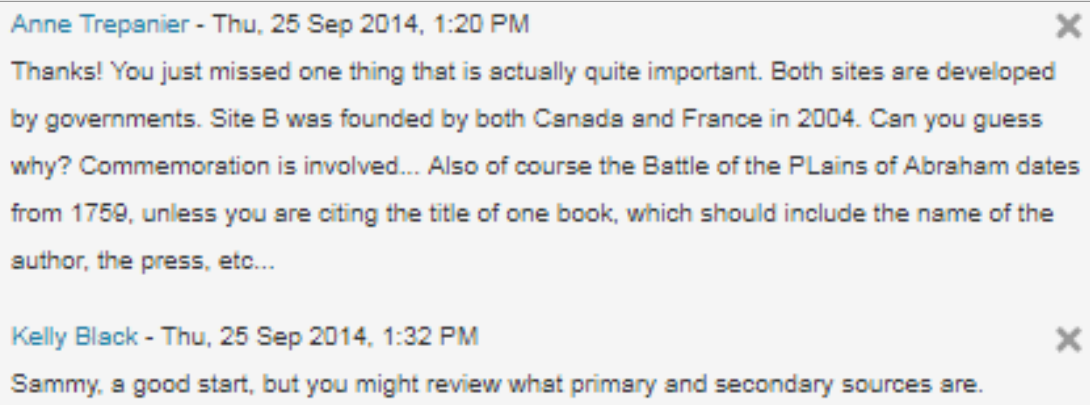

Figure 2. Open feedback for assignment submissions.

In the following weeks after this initial activity, students are asked to put in practice what they have learned by searching for primary sources that belong to one of the three main topics examined in the course: Culture and Identity, Economy, or Constitutional Relations, and to one of the main historical periods covered in the 
course: the Quiet Revolution (1960s), the first referendum (1980), the second referendum (1995), or present time (Figure 3).

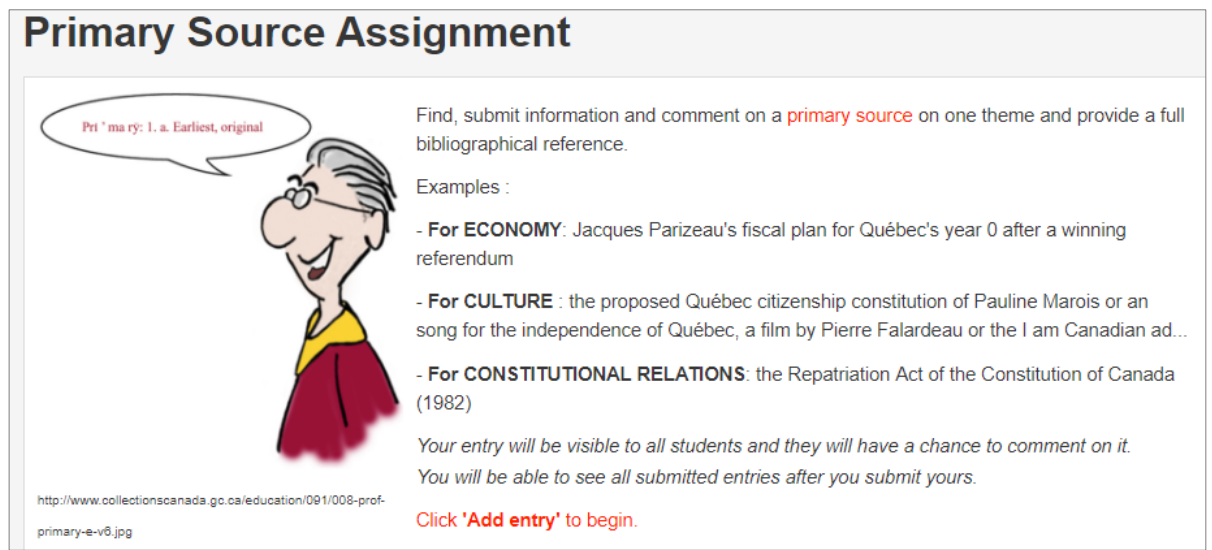

Figure 3. Primary source assignment instructions.

The Database Activity Module is designed to permit students to make a selection of the primary source attributes before uploading it into an activity, and also to offer a rationale for their selection as it relates to a certain context and topic (Figure 4). Students are also encouraged to upload an image related to the primary source.

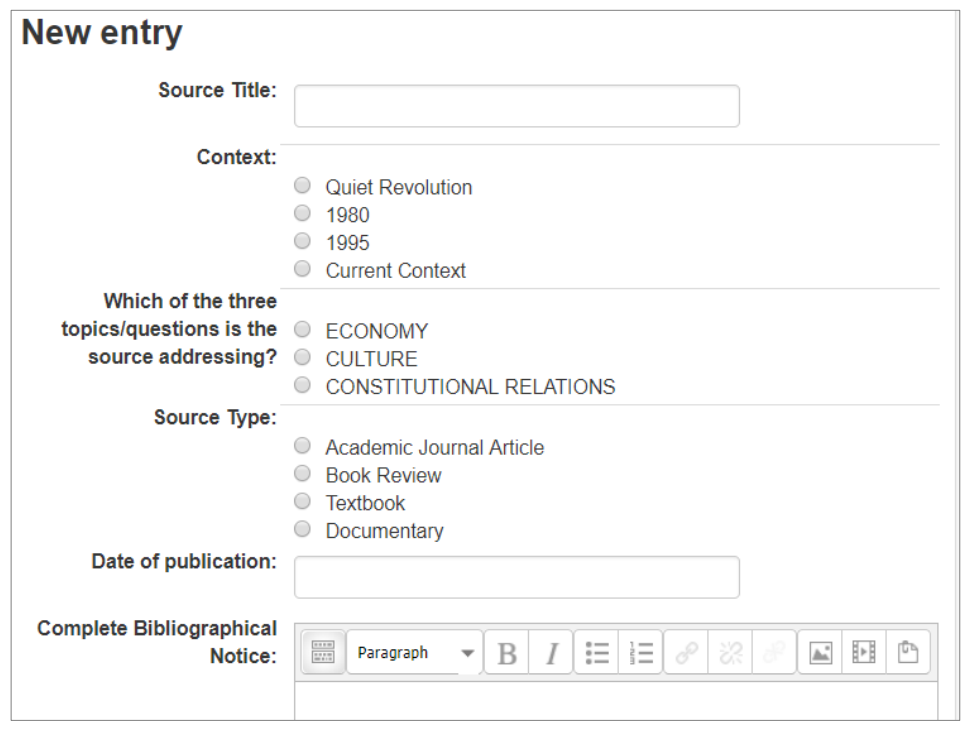

Figure 4. Entering data in the Moodle database module.

Similarly to the previously described activity, an important Moodle database activity feature used in these assignments is allowing students to see all entries immediatly after they upload their own (Figure 5). This feature not only minimizes chances of copying ideas from classmates, it also acts as an immediate reward 
in connecting them to the "communal learning basket." Indeed, once the individual entry is made, it becomes visible to the whole class and open for comments from the teaching staff and classmates.

\begin{tabular}{|c|c|c|c|c|c|}
\hline \multirow[t]{15}{*}{ Ststoent Hame } & Souree titis & Image & Contoxt & The questionat toples pource sodromes & Moro \\
\hline & 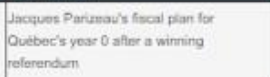 & & 1995 & Econowr & a \\
\hline & The Constitufon Nat of 1902 & 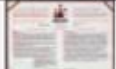 & 1980 & CONSTITUTIONNL RELATIONS & a \\
\hline & Mantestit & 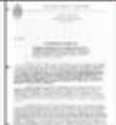 & $\begin{array}{l}\text { aviet } \\
\text { Revoution }\end{array}$ & oulture & a \\
\hline & & & $\begin{array}{l}\text { Oarrent } \\
\text { Canteat }\end{array}$ & Econowr & a \\
\hline & Dectiraston of the King concerming & Les: & $\begin{array}{l}\text { Ourrent } \\
\text { context }\end{array}$ & Econowr & a \\
\hline & Momale de Canse fart money) & as & $\begin{array}{l}\text { aurrent } \\
\text { canteat }\end{array}$ & EConour & a \\
\hline & 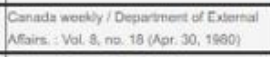 & & 1960 & CUITURE & a \\
\hline & 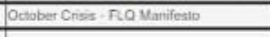 & & & & $a$ \\
\hline & 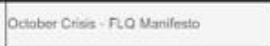 & & $\begin{array}{l}\text { Divet } \\
\text { hevoutuon }\end{array}$ & Culture & $a$ \\
\hline & Ouebec Act 1774 & 트를 & $\begin{array}{l}\text { Duvet } \\
\text { Revouts: }\end{array}$ & CONSTIRUTIONUL RELATIONS & a \\
\hline & 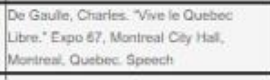 & & $\begin{array}{l}\text { Ouviel } \\
\text { Revolution }\end{array}$ & oultues & a \\
\hline & Whe be Quebose Lare & & $\begin{array}{l}\text { Ouivi } \\
\text { Revalution }\end{array}$ & CuLture & a \\
\hline & Iam a Caraban & & $\begin{array}{l}\text { Oanrent } \\
\text { Conniest }\end{array}$ & Culture & a \\
\hline & Gens du pays & & 1990 & Cultunas & $a$ \\
\hline
\end{tabular}

Figure 5. Crowdsourcing and sharing the collected primary sources: List view mode.

One of the main advantages of this adaptable Moodle activity is that it allows the data to be displayed in an easy-to-browse and searchable format in a list view mode (Figure 6). This feature becomes essential when preparing for the capstone activity: a class final debate. 


\begin{tabular}{|c|c|c|}
\hline \multirow[t]{2}{*}{ Search CULTURE } & Sort by Tim & ne added \\
\hline & Advanced search & Save settings \\
\hline Source Title & Context & The topic/question source addresses \\
\hline $\begin{array}{l}\text { Canadian Federalism and Quebec } \\
\text { Sovereignty }\end{array}$ & Current Context & CULTURE \\
\hline $\begin{array}{l}\text { Is Quebec Culture Doomed to } \\
\text { Become American? }\end{array}$ & 1995 & CULTURE \\
\hline $\begin{array}{l}\text { A Community in Transition: The } \\
\text { Jews of Montreal }\end{array}$ & Current Context & CULTURE \\
\hline $\begin{array}{l}\text { Interculturalism or } \\
\text { Multiculturalism? }\end{array}$ & Current Context & CULTURE \\
\hline Interculturalism or Multiculturalism & m Current Context & CULTURE \\
\hline $\begin{array}{l}\text { "Is Quebec Nationalism Just? } \\
\text { Perspectives from Anglophone } \\
\text { Canadians }\end{array}$ & Current Context & CULTURE \\
\hline Taylor and Francis Online & Current Context & CULTURE \\
\hline $\begin{array}{l}\text { Regional Political Cultures in } \\
\text { Canada }\end{array}$ & Quiet Revolution & CULTURE \\
\hline
\end{tabular}

Figure 6. Searching and sorting based on source attributes in Moodle database activity.

After identifying sources they want to read more about, based on selected attributes, students click on the "More" button (Figure 5) to view a full single entry (Figure 7). When reflecting on a source selection, students are encouraged to use proper citation and referencing.

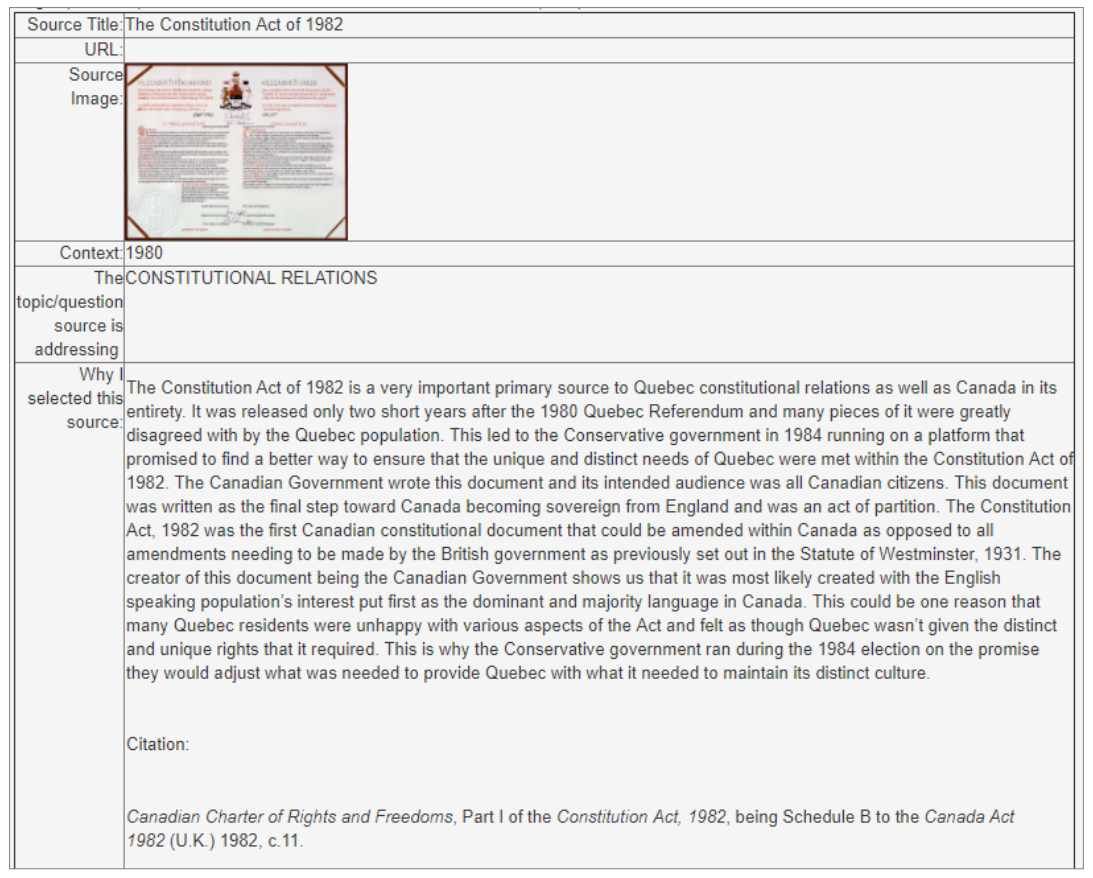

Figure 7. Individual student database entry: Single view mode.

All previously described activities progressively prepare students for course capstone activities, such as an online class debate and final essays, where they are prompted to refer to primary and secondary sources collected by all classmates, and also to those shared by the instructor. Since the entries made in a Database Activity Module are easily searchable by either context or time period, students have a wide range of 
crowdsourced, described, properly cited, and evaluated sources, which they can reference in the final class activities.

Based on student feedback, two aspects of the designed online activities play a large role in their learning experience. Indeed, knowing that individual work and contributions will be visible to the whole class, and being able to compare entries, serve as a motivational factor to improve the level of engagement and quality of submitted work.

\section{Conclusion}

Recent emphasis on providing more experiential learning opportunities for today's students comes as a natural reaction to a long tradition of school-based teaching and learning environments. For instance, situated in a physical classroom, students were expected to, often passively, intake the content provided by a teacher, while later engaging in learning activities, mainly at the individual level, and submitting assignments directly to the teacher. This typical learning method often did not provide much opportunity for individual students to observe and take part in the group learning process and compare personal learning outcomes with those of their classmates. When creating learning experiences in new modalities, there seems to be a value in reminding ourselves of our long-enduring learning and motivational contexts, and accepting the "need to delve into the hunter-gatherer world that shaped us, the world that we subconsciously still inhabit." (Harari, 2015, p. 40). Returning to historically proven effective learning opportunities that enable students to explore and immediately put in practice what they have learned, while sharing experiences with the group and engaging in a complex "student-student-teacher-content" fourdimensional interaction matrix, seems to be the natural progression of organized education.

These "new," albeit historically "old," types of learning experiences do not need be constrained by the mode of learning, they can only be constrained by the mode of thinking, teaching, and designing courses. In the digital age, the teacher can still guide towards selected orchards, but can also encourage a search for new ones and provide opportunities for learners to share their discoveries. This new approach to learning enabled by technology results not only in predefined and quickly validated learning outcomes, but also in those coloured in hues that reflect the unique community and context in which they have emerged.

Additionally, the growing need to improve students' digital literacy skills and prepare them for future careers requires teaching methods that provide opportunity for the development of both the skills and experiences they need to succeed in life after university. This means incorporating learning activities that include digital technology as "a gateway to a comprehensive, demanding, collaborative, and all-consuming interactive experience that stimulates learning of key skills" (Lee, 2015, p. 458). When designed with a focus on learning outcomes, these types of activities can be used to encourage students to engage in a process of online exploration and critical thinking, to share their findings with the class, and to help teachers "create a culture that can support those values and beliefs that they consider to be important for today's learners" (Bates, 2015, Culture and New Learning Environments section, para. 2). The nature of the individual undertakings enabled by technology allows for flexible and accessible learning, while experiential, authentic, and memorable activities can transform it from a solitary to a meaningful individually constructivist learning experience, as well as a collaborative experience, which should be the premise of higher education (Vaughan, Cleveland-Innes, \& Garrison, 2013). The presented case confirms that carefully 
crafted online instructional design strategies can contribute to a flexible and rich learning environment that transcends space and time, and yet keeps learners and the teacher closely interconnected, engaged, and accountable for both individual and group success in knowledge "hunting, gathering and sharing" activities in the digital age. 


\section{References}

Bates, A. W. (2014, December 1). Can you do experiential learning online? Assessing design models for experiential learning [Blog post]. Online Learning and Distance Education Resources. Contact North. Retrieved from https://www.tonybates.ca/2014/12/o1/can-you-do-experiential-learningonline-assessing-design-models-for-experiential-learning/

Bates, A.W. (2015). Teaching in a digital age: guidelines for designing teaching and learning. Vancouver BC: Tony Bates Associates Ltd. ISBN: 978-0-9952692-0-0.

Digital Literacy, Libraries, and Public Policy. (2013, January). Report of the office for information technology policy's digital literacy task force. American Library Association. Retrieved from http://www.districtdispatch.org/wpcontent/uploads/2013/01/2012 OITP digilitreport 1222 13.pdf

Geary, D. C. (2007). Educating the evolved mind: Conceptual foundations for an evolutionary educational psychology. In J.S. Carlson \& J.R. Levin (Eds), Educating the evolved mind (Vol.2; pp. 1-99). Greenwich, CT: Information Age Publishing.

Gray, P. (2009). Play as a foundation for hunter-gatherer social existence. American Journal of Play, 1(4), 476-522. Retrieved from http://www.journalofplay.org/sites/www.journalofplay.org/files/pdfarticles/1-4-article-hunter-gatherer-social-existence.pdf

Harari, Y. N. (2015). Sapiens: A brief history of humankind. New York: Harper.

Kirschner, P., Sweller, J., \& Clark, R. (2006). Why minimal guidance during instruction does not work: An analysis of the failure of constructivist, discovery, problem-based, experiential, and inquiry-based teaching. Educational Psychologist, 41(2). doi: 10.1207/s15326985ep4102_1

Lee, T. (2015). Technology-based experiential learning: A transnational experiment. Journal of Legal Education, 64(3), 455-479. Retrieved from https://jle.aals.org/cgi/viewcontent.cgi?article=1033\&context=home

Vaughan, N. D., Cleveland-Innes, M., \& Garrison, D. R. (2013). Teaching in blended learning environments: Creating and sustaining communities of inquiry. Edmonton: AU Press.

\section{Athabasca University}

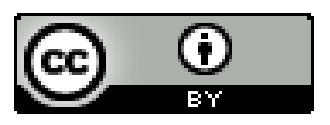

